\title{
Evaluation of the Corrosion Resistance of AISI 316 Stainless Steel Filters
}

\author{
Luzinete Pereira Barbosa*, Isolda Costa \\ Instituto de Pesquisas Energéticas e Nucleares, IPEN/CNEN-SP \\ Centro de Ciência e Tecnologia de Materiais, Laboratório de Corrosão \\ C.P. 11049, Pinheiros, 05422-970 São Paulo, Brazil
}

Received: November 23, 2003; Revised: December 28, 2004

\begin{abstract}
In this investigation, the corrosion resistance of AISI $316 \mathrm{SS}$ filters prepared with powders in the size ranges 74-44 $\mu \mathrm{m}$ and 210-105 $\mu \mathrm{m}$ and compacted with pressures of $300 \mathrm{MPa}$ and $400 \mathrm{MPa}$ has been evaluated in naturally aerated $0.5 \mathrm{M} \mathrm{H}_{2} \mathrm{SO}_{4}$ solution at $25^{\circ} \mathrm{C}$. Weight loss of filters manufactured with compacting pressure of $400 \mathrm{MPa}$ were significantly higher than that of filters compacted at $300 \mathrm{MPa}$. The filter compacted at $400 \mathrm{MPa}$ had higher carbon and nitrogen contents compared to those compacted at $300 \mathrm{MPa}$. The former also had chromium rich precipitates and oxides in the grain boundaries. The pores in filters compacted at $400 \mathrm{MPa}$ were smaller than in filters compacted at $300 \mathrm{MPa}$. Smaller pores favor the formation of concentration cells and consequently, increased crevice corrosion.
\end{abstract}

Keywords: sintered stainless steels, filters, corrosion, AISI 316

\section{Introduction}

Stainless steel (SS) filters produced by Powder Metallurgy (P/M) techniques find many applications in various industries such as chemical, petrochemical, nuclear and medical. These filters are used for solid-liquid separation, gas filtering, separation of antibiotic crystals, or in any application where contaminants are detrimental to the final product $^{1}$. In many of these applications, the filters are exposed to corrosive environments, and should therefore have adequate corrosion resistance. Other important characteristics of filters are uniform distribution of pores, high permeability at specific pore sizes, and high regeneration ability.

The pores in materials produced by $\mathrm{P} / \mathrm{M}$ decrease the corrosion resistance of these materials compared to similar materials produced by conventional metallurgy. Other factors that affect the corrosion resistance of austenitic SS filters are the carbon and nitrogen content that could cause sensitization. The presence of interconnected pores in materials produced by $\mathrm{P} / \mathrm{M}$ has been associated, in the literature, to inferior corrosion resistance, compared to materials produced by conventional metallurgy ${ }^{2,3}$. According to literature ${ }^{4-8}$, the stagnant electrolyte in the interconnected pores leads to the development of hydrogen concentration cells between the external and the internal surfaces of the pores. According to Reen and Hughes ${ }^{8}$, large potential differences are established between the small anodic areas within the pores, and the outer passive areas surrounding the pores. This large potential difference causes continued corrosion within the pores, while the regions around the pores act as a cathode and therefore remains protected. Therefore, the fewer the number of interconnected pores, the higher the corrosion resistance. However, interconnected porosity is an essential characteristic of filters.

Porosity characteristics, such as mean pore size, pore size distribution, and percentage of interconnected pores depend on the manufacturing process parameters. The development of filters with satisfactory corrosion resistance must therefore consider optimization of process parameters and these include metal powder characteristics (size, geometry, surface) compacting pressure, sintering atmosphere and sintering temperature.

In this investigation, the corrosion resistance of AISI $316 \mathrm{SS}$ filters prepared using powders in the size ranges $74-44 \mu \mathrm{m}$ and $210-105 \mu \mathrm{m}$, and compacted with pressures of $300 \mathrm{MPa}$ and $400 \mathrm{MPa}$ has been evaluated in naturally aerated $0.5 \mathrm{M} \mathrm{H}_{2} \mathrm{SO}_{4}$ solution at $25^{\circ} \mathrm{C}$.

\section{Materials and Methods}

Water atomized AISI $316 \mathrm{~L}$ powders in the size ranges $74-44 \mu \mathrm{m}$ and $210-105 \mu \mathrm{m}$ were used to produce the filters. The carbon content of the powders was analyzed and found to be $0.024 \%$. The filters were compacted in a cylindrical die $40 \mathrm{~mm}$ in diameter, at pressures of 300 and $400 \mathrm{MPa}$. After compaction the filters were sintered in a continuous pusher-type furnace at $1200{ }^{\circ} \mathrm{C}$ for 1 hour in $75 \% \mathrm{H}_{2}-$ $25 \% \mathrm{~N}_{2}$ atmosphere. The total and interconnected porosity were determined by measuring the geometric and hydrostatic densities. A theoretical density of $7.96 \mathrm{~g} / \mathrm{cm}^{3}$ was used. The mean pore diameter was determined by mercury porosimetry. The porosity characteristics of the filters are shown in Table 1.

After the corrosion test, the corrosion resistance of the filters was evaluated from weight loss measurements, through chemical analysis by atomic absorption spectroscopy of the solutions where the specimens were immersed and from observations of the filter surface using a scanning electron microscope coupled to X-ray dispersive (EDX) analysis facilities.

The specimens for weight loss measurements were cut to size and the external surface area was approximately $7 \mathrm{~cm}^{2}$. Subsequently, these specimens were degreased with acetone, dried in an oven at $200{ }^{\circ} \mathrm{C}$ for two hours, and weighed. The specimens were then immersed in the test solution (naturally aerated $0.5 \mathrm{M} \mathrm{H}_{2} \mathrm{SO}_{4}$ ). After predetermined periods, the specimens were removed from the solution, washed with acetone, rinsed with de-ionized water in an ultrasonic bath, dried in an oven at $200{ }^{\circ} \mathrm{C}$ for two hours, and then weighed.

Figures $1 \mathrm{a}$ and $1 \mathrm{~b}$ show filters compacted at $300 \mathrm{MPa}$ using powders in the size ranges, $74-44 \mu \mathrm{m}$ and $210-105 \mu \mathrm{m}$, respectively.

\section{Results and Discussion}

Weight loss as a function of immersion time is shown in Figure 2. It can be seen that for filters prepared with powder in the size range 210-105 $\mu \mathrm{m}$ and compacted at $400 \mathrm{MPa}$, there is an initial period, 
Table 1. Porosity characteristics of the filters.

\begin{tabular}{|c|c|c|c|c|}
\hline \multirow{2}{*}{$\begin{array}{l}\text { Powder size } \\
\text { Range }(\mu \mathrm{m})\end{array}$} & \multirow{2}{*}{$\begin{array}{c}\text { Compacting Pressure } \\
(\mathrm{MPa})\end{array}$} & \multicolumn{2}{|c|}{ Porosity (\%) } & \multirow{2}{*}{$\begin{array}{c}\text { Mean Pore } \\
\text { Diameter }(\mu \mathrm{m})\end{array}$} \\
\hline & & Total & Interconnected & \\
\hline \multirow[t]{2}{*}{$(74-44)$} & 300 & 27 & 21 & 9.2 \\
\hline & 400 & 23 & 18 & 6.0 \\
\hline \multirow[t]{2}{*}{$(210-105)$} & 300 & 27 & 23 & 12.8 \\
\hline & 400 & 30 & 24 & 8.1 \\
\hline
\end{tabular}

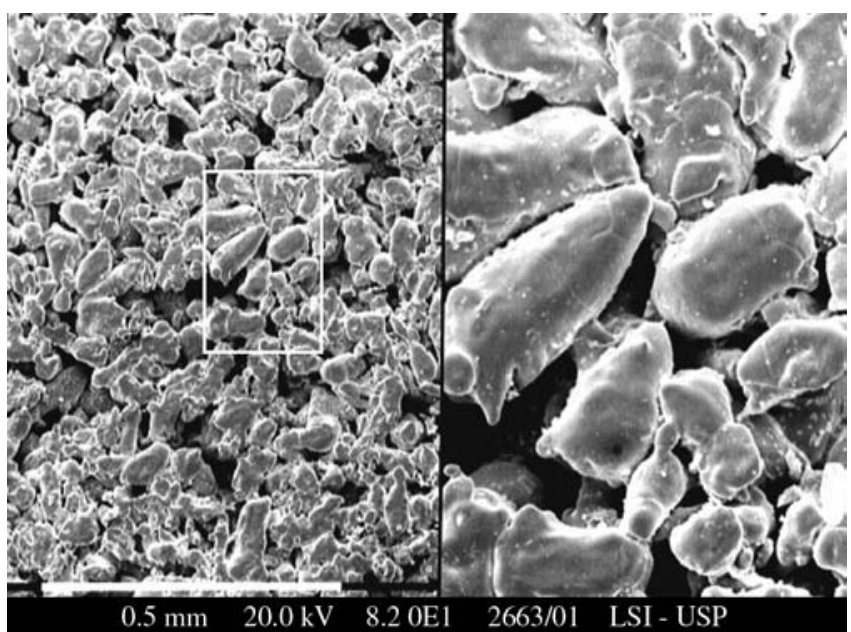

(a)

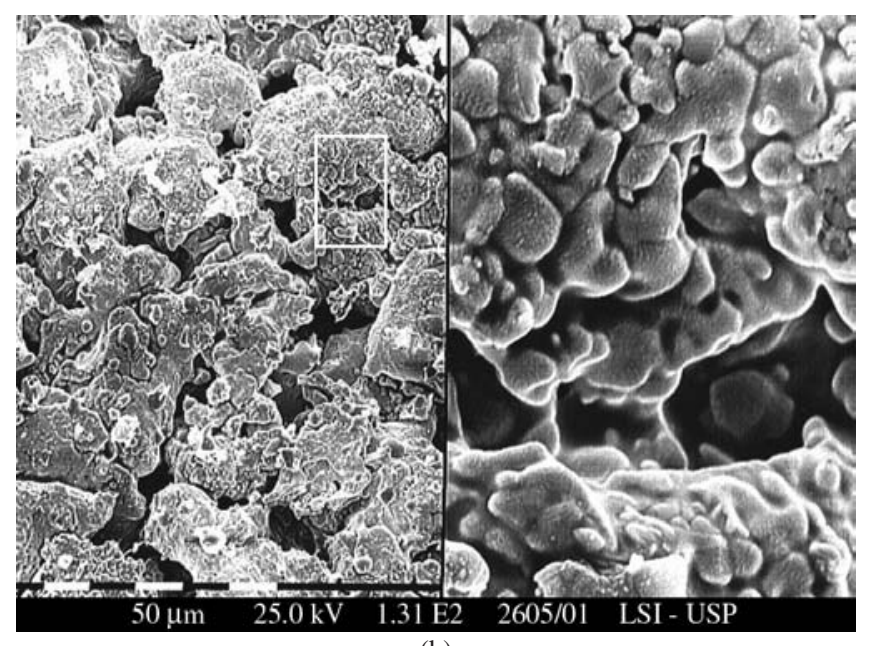

(b)

Figure 1. Filters before the corrosion test: a) produced with powders in the size range $74-44 \mu \mathrm{m}$; b) produced with powders in the size range $210-105 \mu \mathrm{m}$. Both filters were compacted at $300 \mathrm{MPa}$.

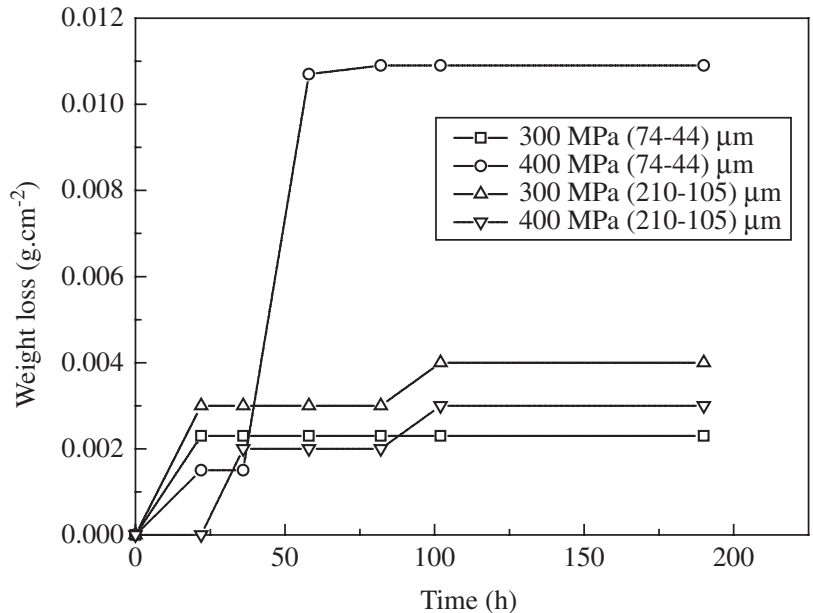

Figure 2. Weight losses of filters after increasing times of immersion in naturally aerated $0.5 \mathrm{M} \mathrm{H}_{2} \mathrm{SO}_{4}$ solution.

approximately 24 hours, during which its weight does not change with time. After this initial period, the weight loss kinetics of filters produced with the larger powders, $210-105 \mu \mathrm{m}$, and at the two compacting pressures were similar. For filters prepared with the smaller powders 74-44 $\mu \mathrm{m}$, and at compaction pressure of $300 \mathrm{MPa}$, the weight losses were much lower than for filters compacted at $400 \mathrm{MPa}$. For the former, a large increase in weight loss occurred between 40 and 60 hours of immersion; but after 60 hours, till the end of the test (180 hours), no significant weight change occurred. All filters showed stable weight values after 100 hours of immersion.

Despite the reduced porosity in the filters prepared with the finer powders (74-44) $\mu \mathrm{m}$ and compacted at $400 \mathrm{MPa}$, compared to that compacted at $300 \mathrm{MPa}$, higher weight losses were observed in the first filter during the whole test period. One of the possible reasons for this apparent discrepancy is the larger pore size in the filter compacted at the lower pressure. Easier access of solution and oxygen inside the wider pores could have promoted the formation and/or reparation of a protective layer, resulting in the decreased corrosion rate. On the other hand, lack of adequate renewal of solution inside the narrow pores, and the slower diffusion of oxygen through these pores, could have prevented restoration of the protective layer at local defects. Additionally, the formation of concentration cells in the filters prepared with the finer powders and compacted at $400 \mathrm{MPa}$ must have led to decreased corrosion resistance. In filters compacted at $400 \mathrm{MPa}$, the very low weight losses in the first hours of immersion could be indicative of an incubation period. It is believed that after this incubation period, the inner surfaces of the pores work as anodic sites and the external surface as the cathodic regions.

Another possible reason for the decreased corrosion resistance of filters prepared with the finer powders and compacted at $400 \mathrm{MPa}$ is its higher carbon content as a contaminant, compared to the other filters. The carbon and nitrogen contents of the starting powders were $0.024 \%$ and $0.096 \%$, respectively, and the results in Table 2 show that contamination of the filters with these elements occurred during the manufacturing process.

The higher carbon content in filters prepared with the finer powders and compacted at $400 \mathrm{MPa}$, favors the precipitation of chromium carbides, and this in fact occurred as will be shown later.

The results of chemical analysis, obtained by atomic absorption spectroscopy, are shown in Table 3, revealing the main alloying elements ( $\mathrm{Fe}, \mathrm{Cr}, \mathrm{Ni}$ and $\mathrm{Mo}$ ) of steel, released into the test solution during 180 hours.

The composition of the solution after immersion test is further proof of the decreased corrosion resistance of the filter prepared with the finer powders and compacted at $400 \mathrm{MPa}$, as compared to that compacted at $300 \mathrm{MPa}$. In fact, the latter filter was the most corro- 
Table 2. Carbon and nitrogen contents in the 316 SS filters.

\begin{tabular}{ccccc}
\hline $\mathrm{P}_{\text {comp. }}$ & \multicolumn{2}{c}{ Carbon content (wt.\%) } & \multicolumn{2}{c}{ Nitrogen content (wt.\%) } \\
& $(210-105) \mu \mathrm{m}$ & $(74-44) \mu \mathrm{m}$ & $(210-105) \mu \mathrm{m}$ & $(74-44) \mu \mathrm{m}$ \\
\hline $300 \mathrm{MPa}$ & 0.10 & 0.12 & 0.56 & 0.25 \\
$400 \mathrm{MPa}$ & 0.05 & 0.31 & 0.44 & 0.44 \\
\hline
\end{tabular}

Table 3. Elements leached from AISI 316 filters into naturally aerated $0.5 \mathrm{M} \mathrm{H}_{2} \mathrm{SO}_{4}$ solution, during 180 hours. Results obtained by atomic absorption spectroscopy.

\begin{tabular}{ccccc}
\hline Filter & Fe & Elements & N \\
$(\mathrm{mg} / \mathrm{mL})$ & $\begin{array}{c}\mathrm{Cr} \\
(\mathrm{mg} / \mathrm{mL})\end{array}$ & $\begin{array}{c}\mathrm{Ni} \\
(\mathrm{mg} / \mathrm{mL})\end{array}$ & $\begin{array}{c}\text { Mo } \\
(\mu \mathrm{g} / \mathrm{mL})\end{array}$ \\
\hline $300 \mathrm{MPa}(74-44) \mu \mathrm{m}$ & 0.004 & 0.024 & 0.004 & - \\
$400 \mathrm{MPa}(74-44) \mu \mathrm{m}$ & 2.930 & 0.460 & 0.620 & 45.38 \\
$300 \mathrm{MPa}(210-105) \mu \mathrm{m}$ & 0.003 & 0.160 & 0.003 & - \\
$400 \mathrm{MPa}(210-105) \mu \mathrm{m}$ & 0.009 & 0.005 & 0.001 & - \\
\hline
\end{tabular}

sion resistant, among the filters that were tested. Therefore, the high corrosion rates observed in the first type of filter are considered to be due to both, the increased contamination and narrower pores.

SEM observation of the filter compacted at $400 \mathrm{MPa}$ after approximately 180 hours of immersion in the test solution showed severe intergranular corrosion attack as shown in Figure 3.

SEM and EDX analysis of the filter compacted at $400 \mathrm{MPa}$ revealed chromium rich precipitates and oxides at the grain boundaries (Figure 4). X-ray diffraction of the precipitates obtained after matrix dissolution revealed that chromium nitrides and carbides were the main types of precipitates in the filters.

Contamination of the filters with carbon and nitrogen occurred during the manufacturing stage and led to the precipitation of chromium rich nitrides and carbides. Nitrogen contamination occurred during sintering, carried out in an industrial furnace. The sintering atmosphere used in this study was $75 \% \mathrm{H}_{2}-25 \% \mathrm{~N}_{2}$ and the sintering temperature, $1200{ }^{\circ} \mathrm{C}$. Carbon contamination probably occurred during the sintering process, but from the reaction products of the binder (polyethylene glycol) and the lubricant (zinc stearate). These compounds form carbon at temperatures above $540{ }^{\circ} \mathrm{C}$, and this should be removed at low temperatures using oxidizing gases such as carbon dioxide before the sintering process. The higher level of contamination of the filter made with finer powders and compacted at the higher pressure could therefore be related to inadequate removal of reaction products originating from the binder/lubricant during sintering. Nitrogen and carbon contamination lead to chromium nitride and/or carbide precipitation and consequently to sensitization of the steel. Sensitization and the pores may have synergistically decreased the corrosion resistance of the sintered steels ${ }^{9}$.

The mean pore diameter of the filters made with the finer powders and compacted at $400 \mathrm{MPa}$ was smaller $(6.0 \mu \mathrm{m})$ than that of the filters compacted at $300 \mathrm{MPa}(9.2 \mu \mathrm{m})$. As mentioned previously, narrow pores act as crevices, favoring the formation of concentration cells that lead to severe localized corrosion. The corrosion mechanism of high density specimens must be different from those that are porous. In the latter, easy access of electrolyte inside the pores may have lead to more uniform attack on the surface layer.

On the other hand, narrow pores act as pits/crevices and the stagnant electrolyte inside the pores causes a crevice corrosion type of mechanism to be operative. In this type of corrosion, concentration cells are created between the external surface and the inner region of the pores ${ }^{6}$. Pores behave as crevices if they are sufficiently large to let the electrolyte in, and, at the same time, are narrow enough

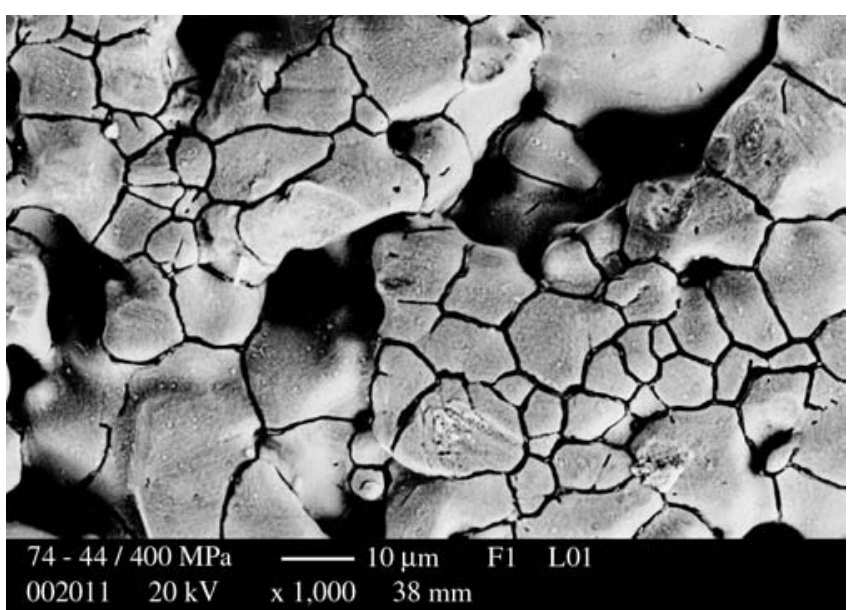

Figure 3. Scanning electron micrograph of filter (prepared with powder in the size range $74-44 \mu \mathrm{m}$ and compacted at $400 \mathrm{MPa}$ ) after 180 hours of immersion in naturally aerated $0.5 \mathrm{M} \mathrm{H}_{2} \mathrm{SO}_{4}$ solution.

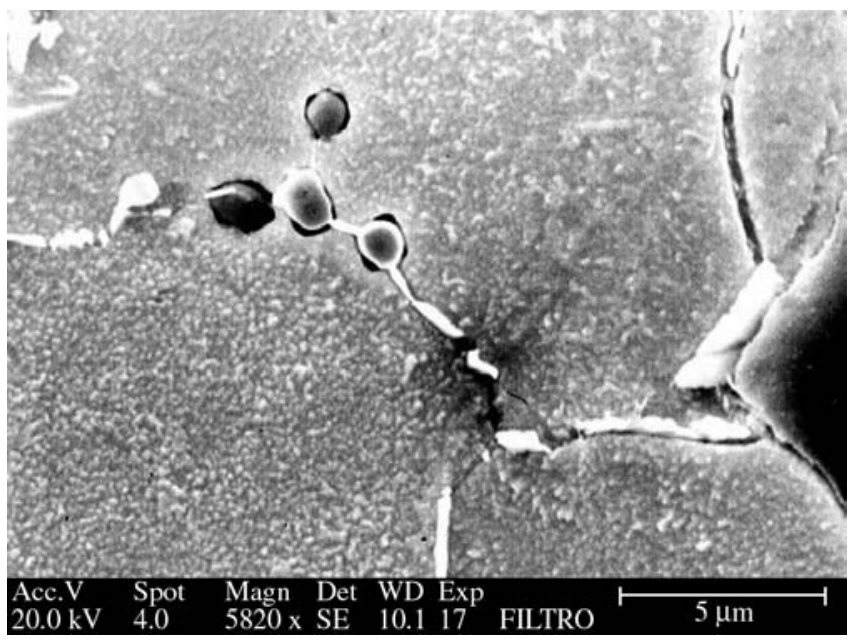

Figure 4. Scanning electron micrograph of filter prepared with powder in the size range $74-44 \mu \mathrm{m}$ and compacted at $400 \mathrm{MPa}$. Precipitates at the grain boundaries are chromium rich and the round particles are aluminum silicates. 
to maintain it stagnant ${ }^{7}$. The stationary electrolyte inside the pores becomes increasingly acidic with time, attacking the passive layer on the pore surface ${ }^{4}$, and consequently promoting corrosion inside the pores. Evidence of this has been observed in this investigation. Examination of the surfaces of the filters after an immersion test showed that the pores in filters produced with the finer powders revealed a greater level of attack compared to those in filters made with coarser powders, mainly those compacted at $400 \mathrm{MPa}$.

\section{Conclusions}

AISI 316 filters made with finer powders $74-44 \mu \mathrm{m}$ and compacted at $400 \mathrm{MPa}$, showed narrower pores and corroded to a greater extent. This filter was also the most contaminated with carbon/nitrogen during sintering. This study proposes that the low corrosion resistance of such a filter was due to: a) electrolyte stagnation inside the pores, thus creating conditions for crevice corrosion and consequently intense corrosion attack; and b) higher level of contamination that led to sensitization and consequently, intergranular corrosion.

\section{References}

1. Molhotra S, Ramakrishnan M. Corrosion behavior of PM stainless steel filters. MPR. 1991; 46(11):48-51.
2. Peled P, Itzhak D. The effect of Ni addition on the corrosion behavior of sintered stainless steel in $\mathrm{H}_{2} \mathrm{SO}_{4}$. Corrosion Science. 1988; 28(4):327-332.

3. Sharon A, Melman N, Itzhak D. Corrosion resistance of sintered stainless steel in $\mathrm{H}_{2} \mathrm{SO}_{4}$ solution. Powder Metallurgy. 1994; 37(1):67-71.

4. Itzhak D, Eghion E. Corrosion behavior of hot pressed austenitic stainless steel in $\mathrm{H}_{2} \mathrm{SO}_{4}$ solutions at room temperature. Corrosion Science. 1983; 23(10): 1085-1089.

5. Itzhak D, Eghion E. An anodic behavior study of an analogical sintered system of austenitic stainless steel in $\mathrm{H}_{2} \mathrm{SO}_{4}$ solution. Corrosion Science. 1984; 24(2):145-152.

6. Peled P, Itzhak D, The corrosion behavior of double pressed, double sintered stainless steel containing noble alloying elements. Corrosion Science. 1990; 30(1):59-65.

7. Seah KHW, Thampuran R, Teoh SH. The influence of pore morphology on corrosion. Corrosion Science. 1998; 40(4-5):546-556.

8. Reen OW, Hughes OG. Evaluation of stainless steel powder metal parts. Precision Metal. 1977; 35:38-40.

9. Itzhak D, Harush S. The effect of Sn addition on the corrosion behavior of sintered stainless steel in $\mathrm{H}_{2} \mathrm{SO}_{4}$. Corrosion Science. 1985; 25(10):883-888 